\title{
Stress-level-dependent microstructure evolution and deformation behaviors during creep age forming of AA2219 alloy
}

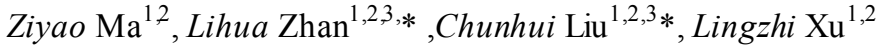 \\ ${ }^{1}$ School of Mechanical and Electrical Engineering, Central South University, Changsha 410083, China \\ ${ }^{2}$ State Key Laboratory of High-Performance Complex Manufacturing, Central South University, Changsha 410083, China \\ ${ }^{3}$ Light Alloy Research Institute, Central South University, Changsha 410083, China
}

\begin{abstract}
Creep age forming (CAF) can shape and strengthen the sheet metals loaded externally at elevated temperature by corresponding creep/stress-relaxation and age hardening. Understanding the deformation and strengthening behavior at different stress levels plays a pivotal role in accurate prediction of CAF. This work experimentally investigates the effect of stress level on the evolution of both properties and microstructures, including precipitates and dislocations, during CAF. The microstructural evolution is characterized in detail by scanning/transmission electron microscopy (S/TEM) and X-ray diffraction (XRD). Stress orienting effect of $\theta^{\prime \prime}$ occurs at low-stress loaded samples and results in a decline in the hardening potential of creep-aging. A bimodal distribution of precipitates consisted of $\theta$ " homogeneously formed in the matrix and $\theta^{\prime}$ heterogeneously formed on dislocations is found in the high-stress loaded samples, giving rise to a significant enhancement of hardening response. In addition, the creep strain increases drastically when the loading stress is higher than the initial yield strength. The relevant mechanisms for the transition of the obtained strength and creep behaviors with the applied stress are discussed based on microstructure observations.
\end{abstract}

Keywords: Creep age forming; Microstructure; Aluminum alloy

\section{Introduction}

Creep age forming (CAF), originally developed to manufacture large integral co mponents of aluminum alloys in the aerospace industry(Holman, 1989; Li et al., 2017; Zhan et al., 2011a), has aroused increased attentions as a promising technique for high performance and reduced cost. The process can simultaneously realize shaping and strengthening of the sheet metals loaded externally at elevated temperature by corresponding creep/stress-relaxation and age hardening. Elastic deformation transforms into plastic deformation through creep/stress-relaxation mechanism(Ho et al., 2004; Xu et al., 2017b), while the alloy strength improves mainly by solid state precipitation and marg inally by dislocation multip lication during CAF (Zhan et al., 201 b; Zhang et al., 2013). The above processes determine the springback and mechanical properties of the CAF formed alloys (Lei et al., 2017; Zhan et al., 2011b; Zhang et al., 2013). When the rib-stiffened sheets are pressed onto the die surface, they will be subject to a complex and nonuniform stress distribution. For instance, the stress at the ribs is much higher than the other areas and can even exceed the yield strength of the Al alloy during the initial loading stage of CAF. The aim of this study is to experimentally investigate the effect of stress level on the evolution of both properties and mic rostructures, including precip itates and dislocations, during CAF. These results will serve as input for accurate modeling and simulation of CAF process, especially that of complex structured component.

Aluminum-Copper AA2219 a lloy is currently widely used to manufacture light weight structural components for aerospace applications. The precipitation sequence in an Al-Cu alloy during artificial age ing treatment is generally accepted as (Biswas et al., 2011; Bourgeois et al., 2011; Guin ier, 1938; Liu et al., 2014; Ma et al., 2016): Supersaturated solid solution $\rightarrow$ G.P. Zones $\rightarrow$ $\theta^{\prime \prime} \rightarrow \theta^{\prime}\left(\mathrm{Al}_{2} \mathrm{Cu}\right)$. Different fro $\mathrm{m}$ simp le art ificial age ing process, the applied stress during CAF creates a thermalmechanical coupled situation and thus adds to the complexity of the precipitation involved. Stress generally could promote the solutes precipitation in many aluminumalloy systems (Hu et al., 2017; Xu et al., 2017a; Yang et al., 2016; Zhang et al., 2013), leading to the acceleration of hardening kinetics. The stress orienting effect, which means precipitates preferentially grow on specific habit planes (only one or two variants are present), of $\theta^{\prime}$ in single-crystal Al-Cu alloy was detected by Zhu and explained by the stress-induced change in lattice parameters and thus interfacial energy anisotropy (Eto et al., 1978; Zhu and Starke, 2001a; Zhu

* Corresponding author: yis-cast@csu.edu.cn (L. Zhan), chunhuiliu@,csu.edu.cn (C.H. Liu) 
and Starke, 2001b). Creep behavior is dictated by the evolution of the related microstructural variables in CAF. At the primary creep stage, the decrease in creep strain rate is associated with the strain hardening caused by a fast increase in dislocation density and the dislocations reconfiguration at later time.

This study systematically investigates the effect of stress, ranged from within the elastic regime to those higher than the initial yield strength, on the creep and ageing process in CAF of an AA2219 alloy. The microstructural evolution is characterized in detail by scanning/trans mission electron mic roscopy (S/TEM), differential scanning calorimetry (DSC) analysis and Xray diffraction (XRD).

\section{Experimental procedures}

The experiments were conducted on a commercial AA2219 alloy whose composition is listed in Table 1. The samples were firstly solution treated at $535^{\circ} \mathrm{C}$ for $35 \mathrm{~min}$ and then water quenched at room te mperature. The uniaxial tensile stress -ageing treatments (creepageing) were performed on a RMT-D10 electronic creep testing machine, at $165^{\circ} \mathrm{C}$ under various stress levels (60MPa, 90MPa, 120MPa, 150MPa, 180MPa, 210MPa). The stress-free-aged samples were placed in the creep testing machine and experienced the same thermal procedures with the stress-aged samples. According to the applied stresses, the stress -ageing treatments are labeled as 60SA, 90SA, 120SA, 150SA and 180SA, respectively. The stress-free-ageing treatment is labeled as SFA. A special group of experiments were also carried out: the samples were loaded (pre-deformed) at the beginning of heating process to $180 \mathrm{MPa}$, which lasts for only $2 \mathrm{~min}$, and then stress-free-aged for the rest of the is othermal ageing at $165^{\circ} \mathrm{C}$ (labeled as 180SFA).

Table 1. Chemical Composition of the AA2219 alloy (wt. \%)

\begin{tabular}{|c|c|c|c|c|c|c|}
\hline $\mathbf{C u}$ & $\mathbf{M g}$ & $\mathbf{M n}$ & $\mathbf{S i}$ & $\mathbf{Z r}$ & $\mathbf{T i}$ & $\mathbf{A l}$ \\
\hline 6.09 & 0.0032 & 0.29 & 0.090 & 0.14 & 0.070 & Bal. \\
\hline
\end{tabular}

The aged samples were subjected to the uniaxial tensile tests on a CMT-5105 test machine and the yield strengths were obtained as $0.2 \%$ offset yield stress. For microstructural observations, the S/TEM samples were prepared by standard method. STEM images were acquired on a Titan $G^{2}$ 60-300 Transmission Electron Microscope. The X-ray diffraction (XRD) tests were carried out on an Advance D8 X-Ray Diffractometer with a scan range from $20^{\circ}$ to $100^{\circ}$ and a scan speed of $0.02^{\circ}$ each step. Differential Scanning Calorimeter (DSC) analys is was performed, using a PerkinElmer DSC8500 instrument, on samples subjected to the same treatment as the $\mathrm{S} / \mathrm{TEM}$ ones.

\section{Results and discussion}

\subsection{Mechanical property}

Figure 1 depicts the evolution of the room-temperature yield strengths of AA2219 stress-free-aged and stressaged at $165^{\circ} \mathrm{C}$ under various stresses. The yield strengths of different stress-aged samples all increase rapidly upon ageing and arrive at the peak values after about $24 \mathrm{~h}$ of ageing. The effect of stress varies with the stress levels: the lower stresses $(60 \mathrm{MPa}, 90 \mathrm{MPa}, 120 \mathrm{MPa})$ weaken the hardening effect while the higher stresses $(150 \mathrm{MPa}$, $180 \mathrm{MPa}$ ) exh ibit different levels of enhancements, as compared with the SFA samples. The weakening degree of different low stresses is almost the same, however the enhancements varies with different high stresses. To clarify this interesting phenomenon, the yield strength at the water-quenched state, which is $141 \mathrm{MPa}$ at room temperature and $138 \mathrm{MPa}$ at $165^{\circ} \mathrm{C}$ after a $35 \mathrm{~min}$ nonis othermal heating process, needs to be noticed. Since the higher stresses $(150 \mathrm{MPa}, 180 \mathrm{MPa})$ are larger than the yield stress at $165^{\circ} \mathrm{C}$, plastic deformation and dislocations should occur during the loading process. It can be confirmed that stresses of different levels all pose a negative effect on the age-hardening response of the alloy, while the positive effect of the high stresses $(150 \mathrm{MPa}, 180 \mathrm{MPa})$ main ly results from dislocation multiplication. This phenomenon is related to the effect of high-stress-induced dislocations on the microstructure evolution and will be discuss ed later.

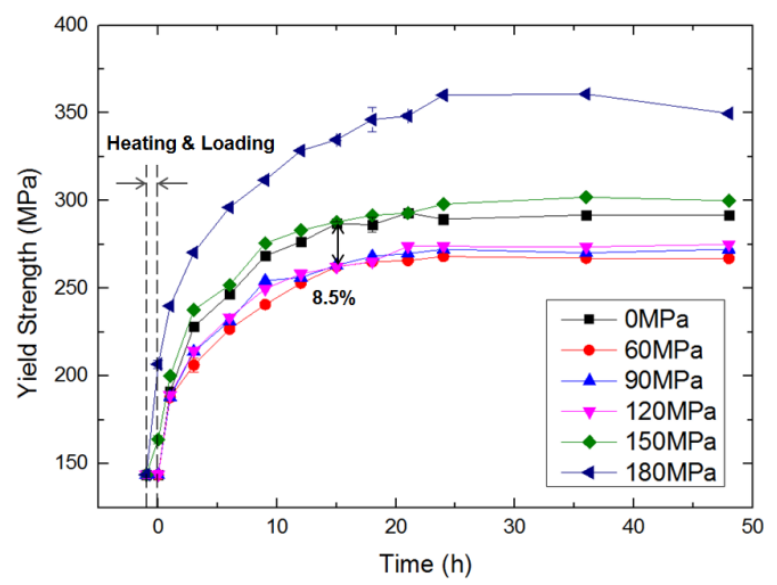

Fig. 1. Hardening curves with time for the creep-aged samples: stress-free-aged at $0 \mathrm{MPa}$, stress-aged at $60 \mathrm{MPa}, 90 \mathrm{MPa}$, $120 \mathrm{MPa}, 150 \mathrm{MPa}$ and $180 \mathrm{MPa}$, respectively.

\subsection{Creep deformation}

The creep strain curves and the creep strain rate curves under different stresses are shown in Fig. 2 and Fig. 3, respectively. When the applied stress is lower than the yield strength $(138 \mathrm{MPa})$ at $165^{\circ} \mathrm{C}$, the total creep strain after $24 \mathrm{~h}$ is very small and does not exceed $0.1 \%$. When the applied stress is higher than the yield strength, the creep strain increases rapidly upon heating. The duration of the primary creep stage increas es significantly. 


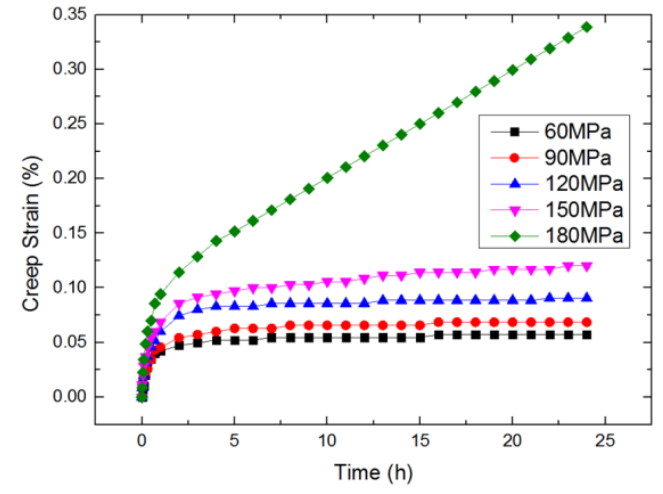

Fig. 2. Creep strain curves of the stress-aged samples.

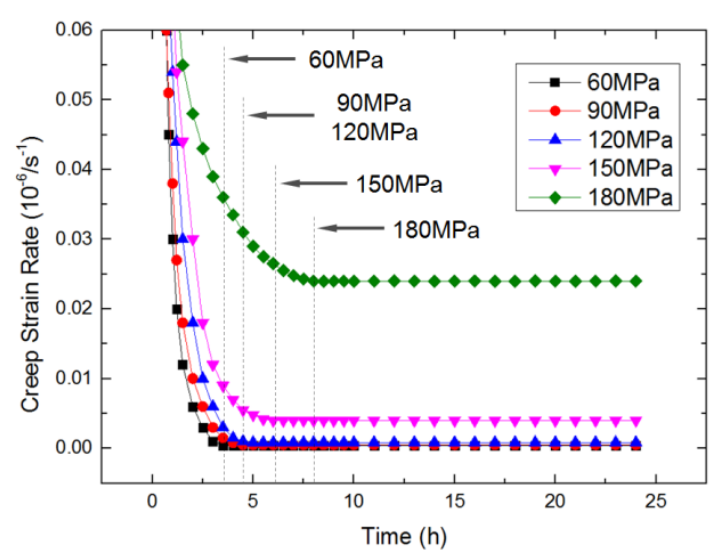

Fig. 3. Creep strain rate curves of the stress-aged samples

The stress exponent, calculated by $n_{s}=\frac{\ln \dot{\varepsilon}_{s}}{\ln \sigma_{0}}$, where $\dot{\varepsilon}_{s}$

is the steady creep strain rate and $\sigma_{0}$ is the applied stress, is introduced to describe the creep mechanis ms (Frost and Ashby, 1982). As displayed in Fig. 4, in the elastic region, the stress exponent is 0.94 , indicating that diffusion creep mechanism controls the creep deformation. In the plastic region, the stress exponent is 9.5, suggesting that dislocation climbing mechanism is controlling. The substantial difference between lowstress and high-stress creep behaviors is caused by the stress-induced dislocations.

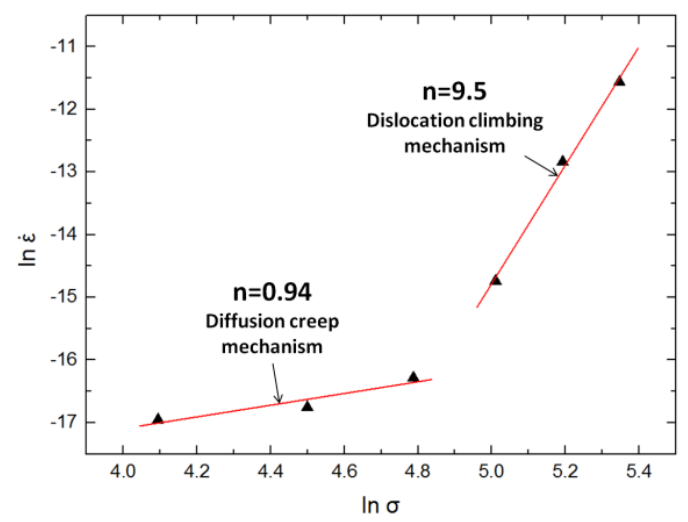

Fig. 4. Log-log plot of creep strain rate versus applied stress: the line slope represents the stress exponents of the creepageing process.

\subsection{Microstructure evolution}

\subsubsection{Dislocation evolution}

The XRD spectrums were analy zed with commercial JADE software to obtain the peak full width at half maximum (FW HM) which serves as input to the modified Williamson-Hall equation (Ungár, 2001) to calculate the dislocation density. The evolutions of dislocation density of different samples are shown in Fig. 5. The dislocation density decrease in a declin ing rate. The difference results fro $m$ the dislocation multiplication during creep-ageing. Moreover, the $180 \mathrm{MPa}$-stressinduced dislocation density is $0.78 \mathrm{E} 14 \mathrm{~m}^{-2}$, much higher than that of the quenched-in dislocation which is too small to be measured accurately using present method.

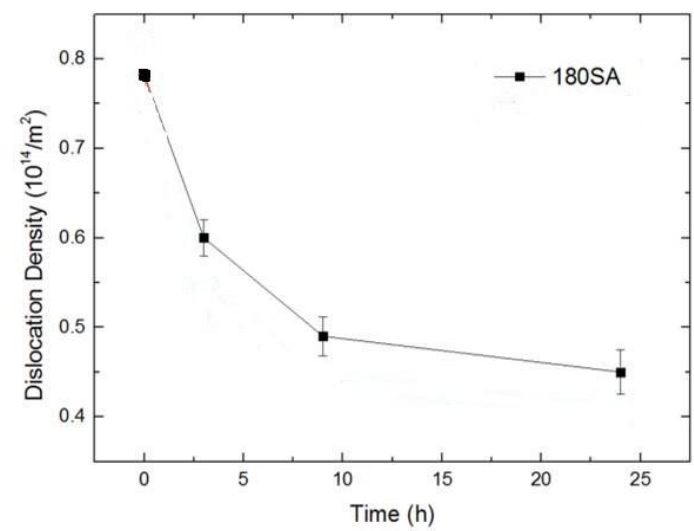

Fig. 5. Dislocation density evolution with creep ageing time in high-stress loaded samples

\subsection{Precipitation behaviors}

\subsubsection{Bi-modal precipitation microstructure}

High-angular dark-field STEM (HAADF-STEM) imaging provides the atomic number $(Z)$ dependent contrast which can be easily interpreted (Howie, 1979; Pennycook and Jesson, 1991). In our case, the region enriched in $\mathrm{Cu}$ would appear brighter than the Al matrix. HAADF-STEM images of the samples under different conditions are shown in Fig. 6 for comparis on. By comparing with HAADF images reported in the literature (Bourgeois et al., 2011; Liu et al., 2014), the precipitates in SFA and 60SA samples are identified as G.P. Zones and $\theta^{\prime \prime}$ phase, while those in 180SFA and 180SA samples are G.P. Zones, $\theta^{\prime \prime}$ phase and $\theta^{\prime}$ phase. According to the literatures (Bis was et al., 2011; Chen et al., 2013), the ageing temperature in this work $\left(165^{\circ} \mathrm{C}\right)$ is too low to activate $\theta^{\prime}$ nucleation in the $\mathrm{Al}$ matrix. In Fig. 
7, it can be seen that the unexpected $\theta^{\prime}$, boxed in the yellow frames, nucleate and grow at the dark regions, whose contrast are usually caused by stress-field around dislocations. Dislocation has a relatively high energy and could facilitate the nucleation of stable $\theta^{\prime}$ (Ku mar et al., 1996). As the $180 \mathrm{MPa}$ stress induces a plasticdeformation of about $2 \%$ at the in itial loading stage, a certain amount of dis locations is generated in 180SA samples. While in SFA and 60SA samples, the dislocations have a much lower density and can't provide preferential nucleation sites for $\theta^{\prime}$, leading to the absence of $\theta^{\prime}$. Therefore, the homogeneous precipitation from the Al matrix and the heterogeneous precipitation at dislocations results in the formation of bi-modal sized precipitates comprised of fine G.P. Zones and $\theta^{\prime \prime}$ as well as large $\theta^{\prime}$ in the high-stress-aged samples (Fig. 6e and f).

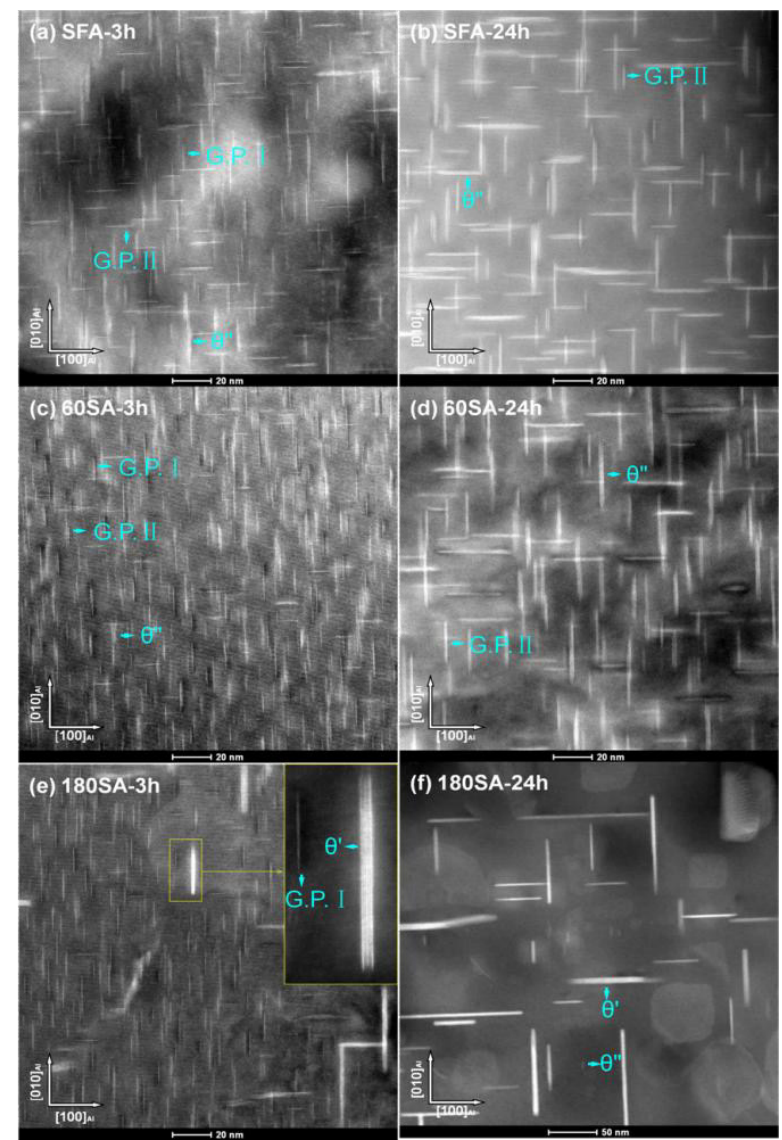

Fig. 6. Low-magnification STEM images of the aged Al-Cu alloy samples:(a) stress-free-aged for $3 \mathrm{~h}$; (c) 60MPa stressaged for $3 \mathrm{~h}$; (e) $180 \mathrm{MPa}$ stress-aged for $3 \mathrm{~h}$; (b) stress-free-aged for $24 \mathrm{~h}$; (d) $60 \mathrm{MPa}$ stress-aged for $24 \mathrm{~h}$; (f) $180 \mathrm{MPa}$ stress-aged for $24 \mathrm{~h}$.

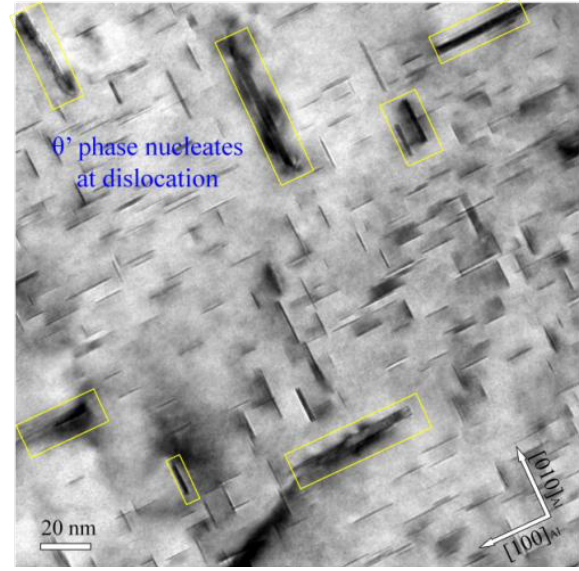

Fig. 7. A bright-field diffraction contrast TEM image of the sample stress-aged for $3 \mathrm{~h}$ under $180 \mathrm{MPa}$. The boxed precipitates represent $\theta$ ' precipitates.

\subsubsection{Stress orienting effect}

When observed along $[001]_{\mathrm{Al}}$ direction, two edge-on variants of the plate-like precipitates are visible in the STEM images (see Fig. 6). Generally, the proportion of these two variants is equal to each other, as shown in Fig. $6 \mathrm{a}$ and $\mathrm{b}$ for the SFA samples. In contrast, the proportion of one particular variant is much higher than the other one in the stress-aged samples (Fig. 6c-f). Another interesting point is that this stress orienting effect (SOE) mainly occurs on the G.P. Zones and $\theta^{\prime \prime}$ phase, while that of the large $\theta^{\prime}$ precip itates in the high-stress-aged sample is not appreciable. As the major microstructural difference, the SOE of precipitates should be responsible for the negative effect of stress on the age hardening. The stress orienting effect was examined in detail in this study. As shown in Fig. 8, the extent of SOE for the stress-aged sample is varied in different grains and even in different regions of the same grain. There are more $(100)_{\mathrm{Al}}$ variants in region $\mathrm{A}$ while more $(010)_{\mathrm{Al}}$ variants in region $\mathrm{C}$. In region $\mathrm{B}$, the numbers of two variants are almost the same. This phenomenon is caused by the varying micro-stress field in different grains, even in the same grain. SOE is caused by stres s-induced anisotropy of interfacial energy of precipitates on various $\{001\} \mathrm{Al}$ planes (Zhu and Starke, 1999, $2001 \mathrm{a})$. A changing orientation relationship between micro-stress and the habit planes is thus expected in the investigated Al-Cu alloy, resulting in a variation of the observed SOE.

The absence of SOE for $\theta^{\prime}$ precipitates suggests a negligible stress effect on the nucleation and growth of precipitates at the randomly distributed dislocations. The stress-field around dislocations should have a much larger stress value than that imposed by the externally applied stress. Therefore, the pre-existed dislocations should play a decisive role on the orientations of the precipitates growing around them. The main strengthening phase in 60SA samples is $\theta$ " while 180SA samples are mostly strengthened by $\theta^{\prime}$, which has no 
evident SOE. The reduction of strength is thus lower when the applied stress changes from $60 \mathrm{MPa}$ to $180 \mathrm{MPa}$, relative to their respective stress-free-aged samples.

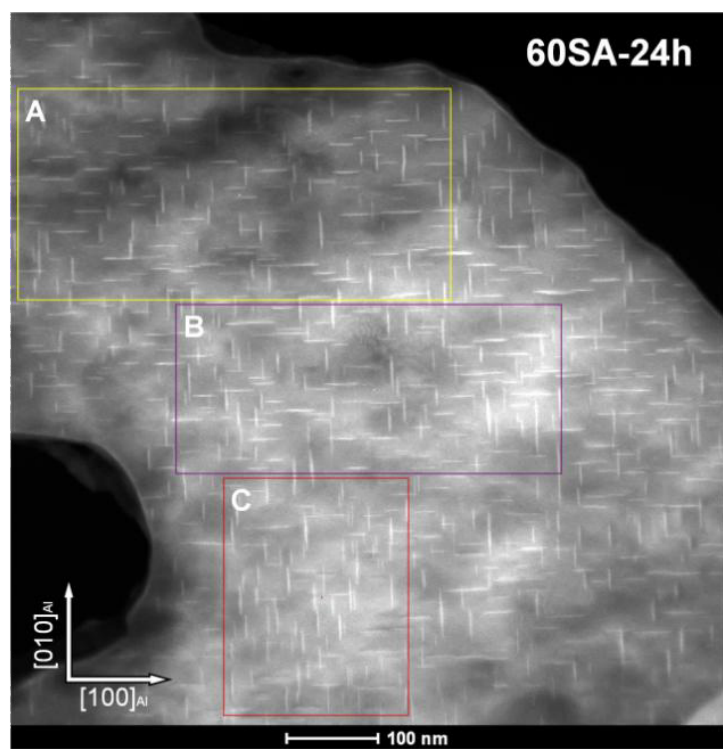

Fig. 8. A low-magnification STEM image of the sample stress-aged for $24 \mathrm{~h}$ under $60 \mathrm{MPa}$.

\subsubsection{Relative volume fraction}

For purpose of simp licity, as G.P. Zones share similar SOE, crystal structure and strengthening mechanism with $\theta$ " phase, G.P. Zones were categorized as $\theta$ " phase hereafter. There are several ways to measure the volume fraction of the precipitates in alloys (Chen et al., 2013; Donnadieu et al., 2011; Rodgers and Prangnell, 2016). In our work, differential scanning calorimeter (DSC) was used to quantify the relative volume fractions (RVF) of the different type precipitates (Rodgers and Prangnell, 2016). The volume proportion of $\theta^{\prime \prime}$ to $\theta^{\prime}$ can be determined with the statistical analys is in S/TEM images, i.e. size and number proportion. In this way, the RVF of $\theta^{\prime \prime}$ and $\theta^{\prime}$ with different ageing treatments are obtained.

In this bimodal precipitation, the evolution of the RVF is very complex due to the $\theta^{\prime \prime} / \theta^{\prime}$ competition for $\mathrm{Cu}$ atoms, which is essential to the nucleation and growth of precipitate. As shown in Fig. 9, the RVF of $\theta^{\prime}$ increases monotonically and differs with that of $\theta^{\prime \prime}$. The RVF of $\theta^{\prime}$ is smaller than that of $\theta^{\prime \prime}$ during the first several hours. After that, the RVF of $\theta^{\prime}$ continues to increase while that of $\theta^{\prime \prime}$ begins to decrease. At the initial creep ageing stage, both $\theta^{\prime \prime}$ and $\theta^{\prime}$ consume $\mathrm{Cu}$ atoms from the $\mathrm{Al}$ matrix, so the RVFs increase together. Since it is harder for semicoherent $\theta^{\prime}$ to nucleate and grow than coherent $\theta$ ", the volume fraction of $\theta^{\prime \prime}$ increases faster than that of $\theta^{\prime}$. The $\theta^{\prime \prime} / \theta^{\prime}$ competition intensifies as ageing proceeds. The metastable $\theta^{\prime \prime}$ phases dissolve while the stable $\theta^{\prime}$ can survive. Thus, the RVF of $\theta^{\prime}$ continues to increase while that of $\theta^{\prime \prime}$ begins to decrease.

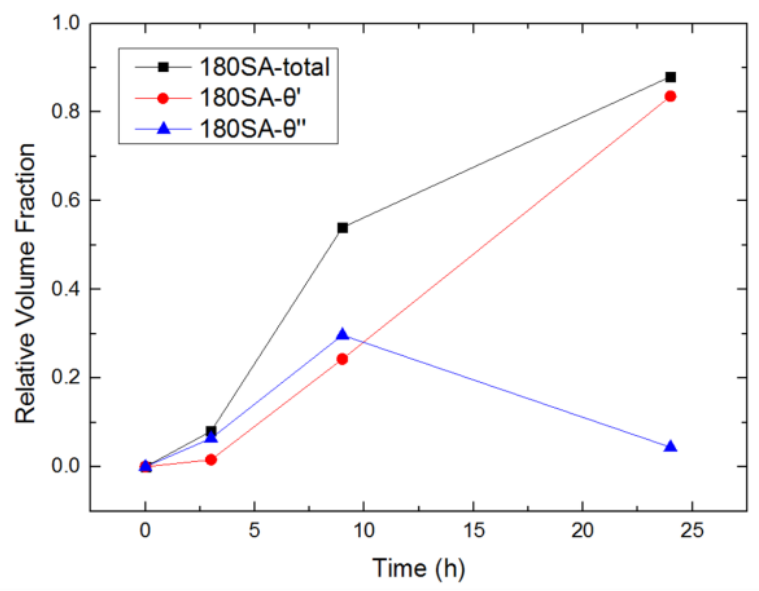

Fig. 9. The evolution of relative volume fraction of precipitates in 180SA samples.

\subsubsection{Precipitates size distribution}

Precip itate sizes were measured with Nano Measurer software for statistical analysis. At least 5 HAADFSTEM images acquired at different regions for each sample were chosen for measuring precip itate sizes. Fig. 10 presents the precipitates size distribution (PSD) of the bi-modal precipitation in the high-stress-aged samples. $\theta "$ is dominant at the early ageing stage in 180SA. The proportion of $\theta$ " shrinks as the ageing proceeds.

The $\theta^{\prime \prime} / \theta^{\prime}$ competition and the applied stress perplex the evolution of the average precipitate dia meters (APD) during creep ageing. During the first several hours of ageing, the growth of both $\theta^{\prime \prime}$ and $\theta^{\prime}$ consumes $\mathrm{Cu}$ atoms from the Al matrix which still contains abundant $\mathrm{Cu}$ solute atoms. During the later several hours (Oswald ripening regime), when the concentration of $\mathrm{Cu}$ ato $\mathrm{ms}$ in the Al matrix is too low, $\theta^{\prime \prime}$ will dissolve rather than grow further if more energetically stable $\theta^{\prime}$ form (Nie and Muddle, 2008; Polmear, 1987). In 180SA sample, the APD of $\theta$ " particles increases firstly and then decreases. Fig. 11 shows the similar PSD in the lowstress-aged samples with the stress-free-aged ones. The APD of $\theta$ " partic les are only slightly larger in 60SA samples (Fig. 12), verifying that the applied low stress has a marginal effect on the growth of $\theta$ " particles. 

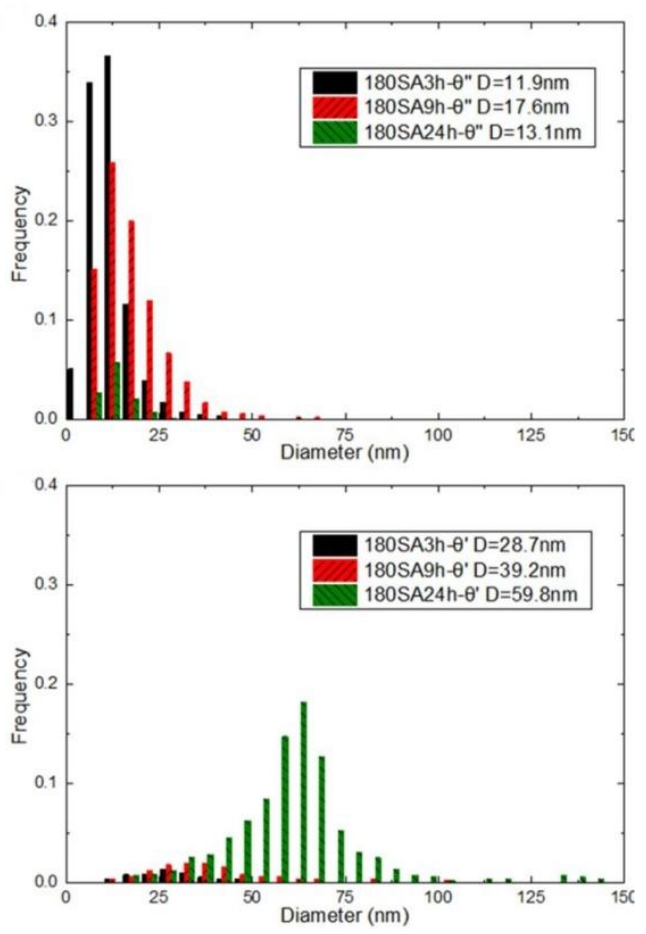

Fig. 10. Size distribution evolution of precipitates (top: $\theta^{\prime \prime}$; bottom: $\theta^{\prime}$ ) during the ageing process ( $D$ is the average diameter) in 180SA samples.
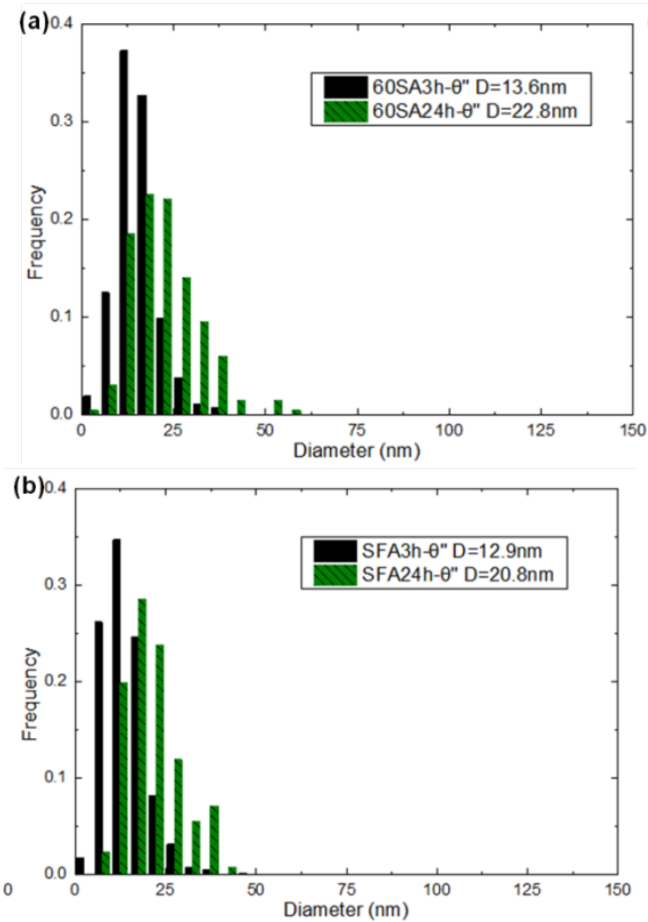

Fig. 11. Size distribution of precipitates in the samples with and without low-stress ageing (D is the average diameter). (a) $\theta^{\prime \prime}$ in 60SA samples; (b) $\theta^{\prime \prime}$ in SFA samples.

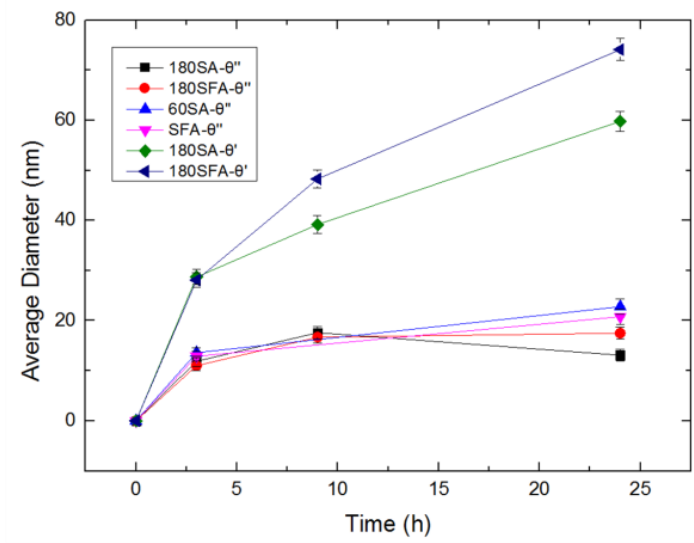

Fig. 12. Average diameters of precipitates under different creep ageing treatments.

\subsection{Microstructure-property relation ship}

After careful examination of the mic rostructure evolution, including the dislocation evolution and precipitation behaviors, it is possible to explain the creep-ageing response observed in Fig. 1. The average strength loss due to the negative stress effect before the peak-aged time decreases fro $\mathrm{m} 8.5 \%$ to $3.7 \%$ when the stress increases from elastic-stress-regime $(60 \mathrm{MPa}-$ $120 \mathrm{MPa})$ to plastic-stress-regime (180MPa). The weakening of the strength contribution from age hardening mainly stems fro $m$ the apparent SOE of $\theta$ " precipitates. The high-stress-induced dislocations give rise to the heterogeneous growth of $\theta$ ' precipitates, which have no detectable SOE. Therefore, the negative stress effect is reduced when the applied stress exceeds the yield strength. The $\theta^{\prime}$ is more effective in strengthening than $\theta^{\prime \prime}$ (Nie and Muddle, 2008). $\theta$ ' precipitates are the major strengthening contributor in the high-stress-aged samples, while $\theta$ " plays a primary role in low-stress-aged samples. The significant strength enhancement in the high-stress-aged samples results from mainly by $\theta^{\prime}$ strengthening and partly by dislocation hardening.

The sketch in Fig. 13 depicts the mic rostructure evolution in stress ageing process. The precipitates occurring during low-stress ageing are dominated by $\theta$ " particles with obvious SOE. Under high-stress ageing, besides preferentially oriented $\theta$ " particles, randomly distributed $\theta$ ' particles at dislocations form continuously. The percentage of $\theta^{\prime \prime}$ is very high in the first several hours but decreases after then due to the gradual growth of $\theta^{\prime}$. Mic rostructure evolution, including dislocation evolution and precipitation behavior, and their relationships with the creep deformation and the mechanical properties are discussed qualitatively in this section. The quantitative relation needs to be investigated to guide the practical application in forming process. 


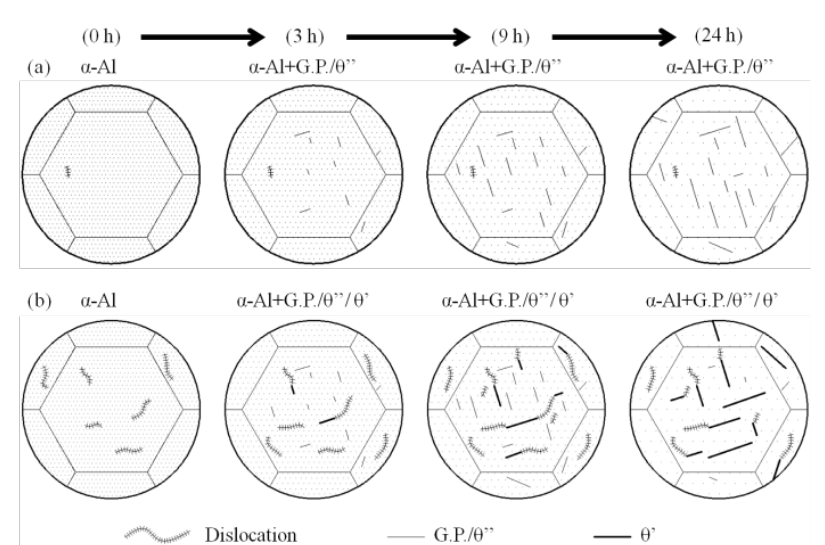

Fig. 13. Evolution of microstructures during stress ageing of AA2219 at: (a) low stress; (b) high stress.

\section{Conclusions}

This study systematically investigated the creep ageing behaviors of AA2219 A1 alloy under varied applied stresses. Microstructural evolution including dislocations and precipitates observed in detail by X-ray diffractometer, Transmission electron microscopy and Differential scanning calorimetry provides new insights into the creep deformation and strengthening mechanis ms. The main conclusions can be summarized as follows:

(1) Applied stress of different levels generally exerts a negative effect on the age hardening response of the alloy. The considerable increase of hardening potential for the high stress applied samples mainly results from dislocations generated at the loading stage.

(2) The creep mechanis m changes from diffusion creep to dislocation climbing when the stress exceeds the initialy ield strength. Creep strain is significantly increased and the primary creep stage is prolonged notably due to the high-stress-induced dislocations.

(3) The strength loss in the stress-aged samples is ascribed to the apparent preferential a lignment of $\theta$ " precipitates (stress-orienting effect, SOE). The dislocations induced at high-stress loading stage give rise to the heterogeneous growth of relatively large $\theta^{\prime}$ precipitates without detectable $\mathrm{SOE}$, leading to the formation of a characteris tic bimodal precipitate morphology. As a result, the negative stress effect is reduced evidently when the applied stress exceeds the yield strength. The $\theta$ " dominates in the first several hours but dissolves gradually due to the continuous growth of more stable $\theta^{\prime}$.

This work is supported by National key R\&D Program of China (2017YFB0306300), National Natural Science Foundation of China (No. 51235010, 51601060), National Key Basic Research Development Plan Funded Project of China (No. 2014cb046602), National Defence Pro gram of China (JCKY2014203A001) and the Fundamental Research Funds for the Central Universities of Central South University (1053320170568).

\section{References}

Biswas, A., Siegel, D.J., Wolverton, C., Seidman, D.N., 2011. Precipitates in Al-Cu alloys revisited: Atom-probe tomographic experiments and first-principles calculations of compositional evolution and interfacial segregation. Acta Materialia 59, 6187-6204.

Bourgeois, L., Dwyer, C., Weyland, M., Nie, J.-F., Muddle, B.C., 2011. Structure and energetics of the coherent interface between the $\theta$ " precipitate phase and aluminium in Al - Cu. Acta Materialia 59, 7043-7050. Chen, Y., Weyland, M., Hutchinson, C.R., 2013. The effect of interrupted aging on the yield strength and uniform elongation of precipitation-hardened Al alloys. Acta Materialia 61, 5877-5894.

Donnadieu, P., Shao, Y., De Geuser, F., Botton, G.A., Lazar, S., Cheynet, M., de Bo issieu, M., Deschamps, A., 2011. Ato mic structure of T1 precipitates in $\mathrm{Al}-\mathrm{Li}-\mathrm{Cu}$ alloys revisited with HAADF-STEM imaging and smallangle X-ray scattering. Acta Materialia 59, 462-472. Eto, T., Sato, A., Mori, T., 1978. Stress-oriented precipitation of G.P. Zones and $\theta^{\prime}$ in an Al-Cu alloy. Acta Metallurgica 26, 499-508.

Frost, H.J., Ashby, M.F., 1982. Deformation mechanism maps: the plasticity and creep of metals and ceramics.

Pergamon press.

Gu inier, A., 1938. Structure of age-hardened alu miniumcopper alloys. Nature 142, 569-570.

Ho, K.C., Lin, J., Dean, T.A., 2004. Modelling of springback in creep forming thick alu minu m sheets. International Journal of Plasticity 20, 733-751. Holman, M.C., 1989. Autoclave age forming large alu minu m a irc raft panels. Journal of Mechanical Working Technology 20, 477-488.

Howie, A., 1979. Image Contrast And Localized Signal Selection Techniques. Journal of Microscopy 117, 11-23. Hu, L., Zhan, L., Shen, R., Liu, Z., Ma, Z., Liu, J., Yang, Y., 2017. Effects of uniaxial creep ageing on the mechanical properties and micro precip itates of Al-Li-S4 alloy. Materials Science and Engineering: A 688, $272-$ 279.

Kumar, K.S., Brown, S.A., Pickens, J.R., 1996. Microstructural evolution during aging of an AlCu LiAgMgZr alloy. Acta Materia lia 44, 1899-1915. Lei, C., Yang, H., Li, H., Shi, N., Zhan, L.H., 2017. Dependences of microstructures and properties on initial tempers of creep aged 7050 alu minu m alloy. Journal of Materials Processing Technology 239, 125-132.

Li, Y., Shi, Z., Lin, J., Yang, Y.-L., Rong, Q., Huang, B.-M., Chung, T.-F., Tsao, C.-S., Yang, J.-R., Balint, D.S., 2017. A unified constitutive model for asymmetric tension and compression creep-ageing behaviour of naturally aged Al-Cu-Li alloy. International Journal of Plasticity 89, 130-149.

Liu, L., Chen, J.H., Wang, S.B., Liu, C.H., Yang, S.S., $\mathrm{Wu}$, C.L., 2014. The effect of Si on precipitation in Al$\mathrm{Cu}-\mathrm{Mg}$ alloy with a high $\mathrm{Cu} / \mathrm{Mg}$ ratio. Materials Science and Engineering: A 606, 187-195. 
Ma, P.P., Liu, C.H., Wu, C.L., Liu, L.M., Chen, J.H., 2016. Mechanical properties enhanced by deformationmodified precipitation of $\theta{ }^{\prime}$-phase approximants in an Al-Cu alloy. Materials Science and Engineering: A 676, 138-145.

Nie, J.F., Muddle, B.C., 2008. Strengthening of an A1$\mathrm{Cu}-\mathrm{Sn}$ alloy by deformation-resistant precipitate plates. Acta Materialia 56, 3490-3501.

Pennycook, S.J., Jesson, D.E., 1991. High-resolution Zcontrast imaging of crystals. Ultra microscopy 37, 14-38. Polmear, I.J., 1987. Role of Trace Elements in Aged Aluminium-Alloys. Materials Science Forum 13-14, 195-214.

Rodgers, B.I., Prangnell, P.B., 2016. Quantification of the influence of increased pre-stretching on microstructure-strength relationships in the $\mathrm{Al}-\mathrm{Cu}-\mathrm{Li}$ alloy AA2 195. Acta Materialia 108, 55-67. Ungár, T., 2001. Dis location densities, arrangements and character from X-ray diffraction experiments. Materials Science and Engineering: A 309, 14-22.

Xu, Y., Zhan, L., Li, W., 2017a. Effect of pre-strain on creep aging behavior of 2524 alu minu m alloy. Journal of Alloys and Compounds 691, 564-571.

Xu, Y., Zhan, L., Xu, L., Huang, M., $2017 b$.

Experimental research on creep aging behavior of Al$\mathrm{Cu}-\mathrm{Mg}$ alloy with tensile and compressive stresses. Materials Science and Engineering: A 682, 54-62. Yang, Y., Zhan, L., Ma, Q., Feng, J., Li, X., 2016. Effect of pre-deformation on creep age forming of AA2219 plate: Springback, mic rostructures and mechanical properties. Journal of Materials Processing Technology 229, 697-702.

Zhan, L., Lin, J., Dean, T.A., 2011a. A review of the development of creep age forming: Experimentation, modelling and applications. International Journal of Machine Tools and Manufacture 51, 1-17.

Zhan, L., Lin, J., Dean, T.A., Huang, M., 2011 b. Experimental studies and constitutive modelling of the hardening of alu miniu m alloy 7055 under creep age forming conditions. International Journal of Mechanical Sciences 53, 595-605.

Zhang, J., Deng, Y., Zhang, X., 2013. Constitutive modeling for creep age forming of heat-treatable strengthening aluminum alloys containing plate or rod shaped precipitates. Materials Science and Engineering: A 563, 8-15.

Zhu, A.W., Starke, E.A., 1999. Strengthening effect of unshearable particles of fin ite size: a computer experimental study. Acta Materialia 47, 3263-3269.

Zhu, A.W., Starke, E.A., 2001a. Stress aging of Al-xCu alloys: experiments. Acta Materialia 49, 2285-2295.

Zhu, A.W., Starke, J.E.A., 2001b. Stress aging of Al-Cu alloys: computer modeling. Acta Materialia 49, 30633069 . 